\title{
Mathematics education and mobile technologies
}

\author{
Kevin Larkin $^{1} \cdot$ Nigel Calder ${ }^{2}$
}

Received: 15 December 2015 / Accepted: 17 December 2015 /

Published online: 23 December 2015

(C) Mathematics Education Research Group of Australasia, Inc. 2015

While relatively new in the digital landscape, mobile technologies and apps offer fresh opportunities to re-envisage some aspects of the mathematics learning experience and enhance students' engagement and mathematical thinking. As well as the visual and dynamic affordances, touchscreens open up more direct interaction with mathematical phenomena, while the mobile affordance allows for easy transference between different learning situations, including home and outdoor, and more flexible ways for students to work collaboratively. A review of recent Research In Mathematics Education in Australasia (RIMEA) volumes indicates that research into the use of digital technologies in mathematics education is not new (e.g. Geiger et al. 2012). Despite their usefulness, perhaps due to their more recent development and uptake, there has not been a similar level of rigourous research conducted into the use of mobile technologies - iPads, iPods, iPhones and Androids in mathematics education. Such research is of particular importance as schools are investing heavily in devices such as these without a concomitant investment in developing practices regarding how such devices may be used to develop conceptual rather than procedural or declarative knowledge (e.g., Calder 2011). The effectiveness of their use in shifting student conceptual understanding is also contingent on associated professional learning for teachers (O'Malley et al. 2013). In addition, the often poor quality of many mathematical apps (Larkin 2015) is recognised as an additional concern when utilising these particular mobile technologies in mathematics education. Concerns such as these provided the impetus for this Special Issue of the Mathematics Education Research Journal (MERJ) on mathematics education and mobile technologies. This issue presents contemporary research, conducted by our colleagues from across the globe, in the use of mobile technologies in mathematics education. Our collaboration, as editors of this special issue, stems from a shared interest in quality mathematics education and how it can be enhanced, but never replaced by, digital

Kevin Larkin

k.larkin@griffith.edu.au

Nigel Calder

n.calder@waikato.ac.nz

1 School of Education and Professional Studies, Griffith University, Gold Coast, Australia

2 University of Waikato, Tauranga, Tauranga, New Zealand 
and mobile technologies. It is from this shared interest that this special issue was conceived and produced.

While there are a range of technologies and associated pedagogical approaches that can be incorporated into mathematics education, it is important to consider the ways that they might reshape the learning experience and influence engagement and understanding. In this issue, the focus clearly concerns either mobile technologies themselves (iPads, iPhones, Androids) or pedagogies associated with the use of mobile technologies (flipped classrooms, twenty-first century learning). In our call for articles, we sought contributions with the following features.

(a) Where the research involves mobile technologies (iPads, Androids, Clickers etc.) rather than computer labs or desktop computers

(b) Where the focus relates to the use of these technologies to support student mathematics learning rather than as a tool to support teachers' work (e.g. marking spreadsheets)

(c) Where the research projects report on transitions in outcomes for students in relation to mathematics learning in either early years, primary, secondary or tertiary contexts both in Australasia and internationally

(d) Where the papers explore the influence of the use of mobile technologies on the affective domain, for instance, on student engagement or motivation

The first four articles in the special issue are focussed on student use of a range of digital and mobile technologies to support their learning. They cover a wide range of ages (early years to secondary school) and discuss research from Italy, Canada, Cyprus and the USA, respectively.

\section{Learning with touchscreen devices: a game approach as strategies to improve geometric thinking}

In this article, Soldano and Arzarello suggest that game-strategic thinking helps students in the construction of logical links between concepts during the "argumentation phase" of the proving process. They base this claim on the logic of inquiry, developed by the Finnish logician - J. Hintikka — and investigate the use of a geometrical game, created for Italian secondary school students, to develop geometric theorems while utilising a multi-touch dynamic geometric environment. This article adapts the theoretical framework of 'instrumental genesis' (Vérillon \& Rabardel 1995) in order to analyse significant actions and dialogues developed by the students while they are solving the game. They argue that the affordances of the digital technology encourage logical thinking, which in turns assists students to think in more mathematically robust ways.

\section{'I'm the best number maker in the galaxy': joint engagement with TouchCounts}

Sinclair, Chorney and Rodney also investigate the affordances of digital technologies in developing mathematical understanding; in this case, in a Canadian early years context 
(students 6-8 years old). In addition to the development of mathematical understanding, the authors also investigate the social and affective nature of children's engagement with TouchCounts: a multi-touch iPad application specifically created for counting and doing arithmetic. This research is unique in the sense that, in order to study these dimensions of engagement in a way that recognises their fundamental intertwinement, the authors use rhythm as a primary unit of analysis. They argue that children uncover mathematical knowledge using rhythm, first in specific contexts and then more generally and further suggest that the rhythm of counting acts as a motivational tool for mathematics engagement.

\section{Mobile technologies in the service of students' learning of mathematics: the example of game app A.L.E.X. in the context of a primary school in Cyprus}

In this article, Kyriakides, Meletiou-Mavrotheris and Prodromou report on the experiences of Cypriot upper primary school students while using A.L.E.X., an educational puzzle game available on iPad or Android. Findings from this study suggest that, while working with A.L.E.X., children identified and processed mathematical knowledge that emerged spontaneously during the course of the game play. As was the case in the Sinclair et al. research, these students also experienced affective gains in terms of enthusiasm and motivation, which helped them to broaden their previously narrow viewpoint of mathematics as being primarily computation and arithmetic.

\section{The role of affordances in children's learning performance and efficiency when using virtual manipulative mathematics touchscreen apps}

This is the fourth and final article directly related to student use of a particular mobile technology. Here, Moyer-Packenham and her research team (primarily from Utah State University) investigate student use of mobile technologies in order to deepen understanding of the role that affordances played in children's (ages 3-8) learning performance and efficiency during their interactions with mathematics apps. This research has important implications for the design of such apps. Qualitative and quantitative video data is used by the authors who identify 95 potential helping and hindering affordances among the 18 apps they trialled. Their results indicate significant changes in children's learning performance and efficiency depending on the different affordances of each app. As was the case in previous research on iPads (Larkin 2013; Moyer-Packenham et al. 2014), individual iPad apps have both helping and hindering affordances, and, to muddy the waters even further, these affordances within the one app have varying effects for different students, dependent on the particular learning approach that best suits the individual student.

The remaining articles in the special issue shift the focus to examinations of possible appropriate pedagogies to best utilise the affordances of the mobile technologies available to classroom and university teachers. A variety of theoretical frameworks are proposed and the educational contexts include very young children, upper primary, junior secondary and senior secondary students, and undergraduate education students. 
As was the case with the first four articles, these pedagogically oriented articles encompass a range of national and international contexts.

\section{Digital natives come of age: pressure, device conflict, novice pedagogical knowledge, and the reality of today's early career teachers' using technological devices to teach mathematics}

Although a disputed notion, the generation labelled by Prensky (2001) as 'Digital natives' now largely comprise the new generation of early career teachers (ECTs). Accompanying this demographical shift are increased community expectations that such teachers can embed information communication technologies (ICTs) effectively into the teaching of mathematics. In this article, Attard and Orlando investigate how four early career primary school teachers use ICT in their teaching of mathematics. Two important factors, developed from the research presented in this paper, suggest that ECTs uses of technology to teach mathematics may be more complicated than first envisaged. First, the teachers appeared to experience 'device conflict', in that the type of device and its particular affordances and limitations was the primary factor that influenced their use in mathematics teaching. Second, the teachers' mathematical knowledge for teaching appeared to be directly related to the ways they used their technology.

\section{Engaging the students through reflection: show and tell tablet technology in mathematics}

Ingram, Williamson-Leadley and Offen report on a qualitative investigation into the use of Show and Tell tablet technology in mathematics classrooms. A Show and Tell app allows the user to capture voice and writing or text in real time. The results of the study indicated that the teachers perceived both the level and the quality of the students' engagement was high and their use enabled the teachers to enact effective pedagogy within their classroom practices. As importantly, through the use of Show and Tell recordings, students' thinking in these New Zealand primary and secondary classrooms became visible to themselves, their teachers and other students.

\section{Using iPads to 'flip the classroom': a case study of a grade 10 mathematics class}

Muir and Geiger investigate a teacher's, and his students', perceptions of the benefits or otherwise of a flipped classroom approach in teaching and learning mathematics. The article starts from the premise that teaching secondary mathematics has a number of challenges, including the expectations that teachers cover the prescribed curriculum, help students learn difficult concepts and prepare students for future studies and, increasingly, that they do so incorporating digital technologies. Their analysis indicates that the teacher and students were positive about their experiences with a flipped classroom approach, that utilised mobile technologies and that students were motivated 
to engage with the teacher-created online mathematics resources. In so doing, the study adds to the limited research literature related to student and teacher perceptions of the affordances of the flipped classroom approach in secondary school mathematics.

\section{Enhancing student engagement through the affordances of mobile technology: a twenty-first century learning perspective on realistic mathematics education}

Several recent curriculum reforms, both here and abroad, aim to address the shortfalls traditionally associated with mathematics education through increased emphasis on higher-order-thinking and collaborative skills, enhanced by harnessing the affordances of digital technology in conjunction with social constructivist pedagogies, contextual scenarios, and/or approaches aligned with Realistic Mathematics Education. This article, by Bray and Tangney, explores how a combination of a transformative, mobile technology-mediated approach facilitated the development of mathematics learning activities in 54 Irish, secondary school students. This article proposes clear, logical connections between aspects of the activity design and their impact on student attitudes and behaviours in learning mathematics. Although situated in an Irish context, there are clear implications in this research for mathematics teaching in many other countries.

\section{Appraising maths educational apps: pre-service teachers' understandings}

The final article in this issue, from Handal, Campbell, Cavanagh and Petocz, reports on a survey of 373 Australian, pre-service students studying primary school education. The technological pedagogical content knowledge (TPACK) model is used as the conceptual framework for the analysis of these students engagement with iPad mathematics apps. The respondents examined three different apps using a purposely designed instrument in regard to their explorative, productive or instructive instructional role. While construct validity could not be established, due to a broad range of variability in responses implying a high degree of subjectivity in respondents' judgments, the qualitative analysis was effective in establishing content validity of the designed instrument.

All articles in this special issue have undertaken the normal blind, peer-review MERJ process, and we deliberately sought national and international colleagues who are both knowledgeable in the field and also not contributing authors for this special issue. Nigel and I would very much like to acknowledge the wonderful reviewing work of the following colleagues, many of whom did several reviews of an article in this special issue. Clearly, without their contributions this special issue would not have been possible. In alphabetical order, they are as follows: Margot Berger, Beth Bos, Alison Clarke-Wilson, Michael Drake, Fiona Ell, Maria-Jesus Gallego-Arrufat, Peter Gates, Merilyn Goos, Peter Grootenboer, Kate Highfield, Romina Jamieson-Proctor, Robyn Jorgensen, Harry Kanasa, Barry Kissane, Allen Leung, Peter Liljedahl, Esther Loong, Thomas Lowrie, Jodie Miller, Judith Mills, Maria Northcote, Greg Oates, Robyn Pierce, Drew Polly, Ann Sacristan, Merilyn Taylor, Melih Turgot, Lida Uribe-Florez and David Wagner. 
This was the first foray that we have both had in an editorial role with MERJ and Springer. We acknowledge the wonderful support and encouragement from the previous MERJ Chief Editor, Professor Robyn Jorgensen and also the current Chief Editor, Professor Peter Sullivan. We look forward to further editorial work with both Robyn and Peter. Finally, we would like to express our support for Ms. Belle Mojado (Springer Press), who answered many, many emails regarding the Springer Editorial systemthank you very much Belle.

The special issue identifies some themes and challenges as the mathematics education community continues to examine the usefulness of mobile technologies to enhance the learning of mathematics, either from the particular affordances of the media that allow teachers to reshape the learning experience, or from the particular pedagogy associated with the technologies. Questions arise when technology is considered in the teaching process: what is the relationship between features of the tablets, the architecture of the apps, and the learning that a reshaped environment might afford? In terms of pedagogy, what approaches might best optimise student engagement and mathematical thinking? As well, how might the notion of scaffolding be re-envisaged to include feedback from digital sources and a greater element of self-assessment? Equity issues concerned with access both within domestic school communities and globally still remain, and require ongoing examination. Some planning and management aspects also need to be considered. What comes first when planning - the mathematics, the app or the pedagogy? What are the best ways to manage the introduction of new apps? Researchers also need to continue to critically examine the influence of mobile technologies on learning across a range of contexts and the ways that they interact with other pedagogical media.

The articles in this special issue reveal considerable potential for mobile technologies to enhance student engagement and mathematical thinking, but the full scope of opportunity and the relationships with other learning approaches are still to be fully unravelled. Nevertheless, they make a considerable and very worthy contribution to further understanding in this critical endeavour.

Kevin Larkin and Nigel Calder (Special Issue Editors)

\section{References}

Calder, N. S. (2011). Processing mathematics through digital technologies: The primary years. Rotterdam, The Netherlands: Sense.

Geiger, G., Forgasz, H., Tan, H., Calder, N., \& Hill, J. (2012). Technology in mathematics education. In B. Perry et al. (Eds.), Research in Mathematics Education in Australasia 2008-2012 (pp. 111-141). Rotterdam, The Netherlands: Sense Publishers.

Larkin, K. (2013). Maths education: Is there an app for that? In V. Steinle, L. Ball \& C. Bardini (Eds.), Mathematics education: yesterday, today and tomorrow (Proceedings of the 36th annual conference of the Mathematics Education Research Group of Australasia). Melbourne, VIC: MERGA.

Larkin, K. (2015) "An App! An App! - My Kingdom for an App”: An 18 month quest to determine whether apps support mathematical knowledge building. In T. Lowrie \& R. Jorgensen (Eds) Digital games and mathematics learning: Potential, promises and pitfalls. Springer Press.

Moyer-Packenham, P. S., Shumway, J. F., Bullock, E., Tucker, S. I., Anderson-Pence, K., Westenskow, A., Jordan, K. (2014). Young children's learning performance and efficiency when using virtual manipulative mathematics iPad apps. Paper presented at the National Council of Teachers of Mathematics Research Conference (NCTM), New Orleans, Louisiana. 
O’Malley, P., Jenkins, S., Wesley, B., Donehower, C., Rabuck, D., \& Lewis, M. E. B. (2013). Effectiveness of using iPads to build math fluency. Paper presented at 2013 Council for Exceptional Children Annual Meeting, San Antonio, Texas.

Prensky, M. (2001). "Digital natives, digital immigrants." From On the Horizon 9(5).

Vérillon, P., \& Rabardel, P. (1995). Cognition and artifacts: A contribution to the study of though in relation to instrumented activity. European Journal of Psychology of Education, 10(1), 77-101. 